\title{
Occipitoatlantoaxial Malformation in a Dog Treated with a Custom-Made Implant
}

\author{
Carina Rotter $^{1} \quad$ Clare Rusbridge $^{1,2} \quad$ Noel Fitzpatrick ${ }^{1}$ \\ ${ }^{1}$ Department of Neurosurgery and Orthopaedics, Fitzpatrick \\ Referrals Ltd, Eashing, Godalming, United Kingdom \\ ${ }^{2}$ School of Veterinary Medicine, University of Surrey, Guildford, \\ Address for correspondence Noel Fitzpatrick, MRCVS, Fitzpatrick \\ Referrals Ltd, Halfway Lane, Eashing, Surrey, GU7 2QQ, \\ United Kingdom (e-mail: noelf@fitzpatrickreferrals.co.uk).
} United Kingdom

VCOT Open 2020;3:e170-e176.

\author{
Abstract \\ Keywords \\ - three-dimensional \\ printed locking plate \\ - patient-specific \\ implant design \\ - cervical vertebral \\ malformation \\ - canine \\ occipitoatlantoaxial \\ malformation
}

Background Occipitoatlantoaxial malformation (OAAM) is reported rarely in dogs and few treatment options are described. The congenital condition is thought to be associated with a proatlas re-segmentation failure resulting in malformation and malalignment of the craniovertebral junction which can result in C1 to 5 myelopathic signs.

Methods Customized three-dimensional printed locking plate with trajectory screw implantation points for the stabilization of the atlantoaxial joint in a dog with OAAM. The dog was evaluated at time points $0,2,6$ and 9 months to determine clinical outcome, degree of fusion, implant positioning and subsidence.

Results New bone formation was noted 9 months after surgery, but complete fusion remained absent, although no implant failure occurred. Clinically, the dog made a good recovery and was able to exercise normally 9 months after surgery. The only residual deficit was a subtle left-sided cervical torticollis.

Clinical Significance This report illustrates a management option and outcome of a dog treated with OAAM. Collaboration between clinicians and engineers provides a new dimension of care for patients with vertebral malformations.

\section{Introduction}

Occipitoatlantoaxial malformation (OAAM) describes triosseous anomalies of the craniovertebral junction affecting the occipital bones, axis and atlas. ${ }^{1-8}$ Case reports of OAAM exist in various species, such as the cat, dog, goat, dromedary camel and wild Japanese serow. ${ }^{1,3-11}$ The condition is thought to be inherited in Arabian horses and Holstein cattle, whereas in other species postnatal fracture, trauma or inflammation has been reported. ${ }^{1,5-9}$ The theory of a developmental anomaly is supported by genetic models where suppression of the Hox-3d gene in mice led to occipitoatlantal assimilation and $\mathrm{C} 2$ deformity. ${ }^{3,12}$ HOX and PAX genes regulate the development of sclerotomes from the somites and their re-segmentation which establishes the vertebral boundaries. ${ }^{12,13}$ Most important in the development of the craniovertebral junction is the proatlas

received

April 14, 2020

accepted after revision

October 1, 2020
DOI https://doi.org/

10.1055/s-0040-1721030. ISSN 2625-2325. sclerotome (4th occipital sclerotome) and 1 st spinal sclerotome. Failure in separation of the proatlas and 1st spinal sclerotome may result in uni-/bilateral, segmental or focal fusion of the atlas to the skull and possible atlantoaxial (AA) malformations. ${ }^{2,5,6,11-14} \mathrm{~A}$ partial or complete fusion of the base of the occiput with the atlas is termed atlantooccipital assimilation, which may lead to chronic AA instability, due to abnormal load onto this segment. ${ }^{1-3,8}$ Prevalence in the human population is 0.08 to $0.3 \%$ and affected individuals can remain asymptomatic or develop myelopathy, typically in the third or fourth decade. ${ }^{2}$ Clinical signs resemble those described in animals-neck pain, torticollis, paresis and ataxia. ${ }^{2-9,11,12,14,15}$ Occipitoatlantoaxial malformation is often associated with hypo-/aplasia of the dens or in humans with an 'os odontoideum', a roundly shaped ossicle not connected to the shortened odontoid process. ${ }^{4,6,11,12,15,16}$ Medical treatment options may be considered if signs occur
License terms Stuttgart · New York

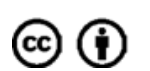


after minor trauma. However, if neurological signs and AA instability are present, as well as an os odontoideum, surgical decompression with $\mathrm{C} 1-2$ fixation and fusion is recommended. ${ }^{1,12,14-16}$ Surgical treatment evaluation of OAAM in domestic animals is limited to reports in one cat and three dogs with different implants and highly variable outcome. ${ }^{4,7,8}$ The purpose of this report is to describe a novel surgical technique and outcome for a dog with OAAM, available due to advances in individual and rapid implant design. Furthermore, we discuss the imaging findings and underlying embryological defects.

\section{Case Description}

\section{Clinical Report and Imaging Observations}

A 1-year-10-month-old, male-entire Border Collie weighing $33.5 \mathrm{~kg}$ was presented with a 4-month acute onset and progressive history of generalized proprioceptive ataxia in all four limbs and a left-sided torticollis after running into a wall. Initially, the dog was managed with meloxicam, then a 4-day course of prednisolone $1 \mathrm{mg} / \mathrm{kg} / \mathrm{d}$ and amoxicillin/clavulanic acid at his family veterinarian. Due to lack of improvement, he was presented 3 weeks after the initial trauma to a referral centre. Neurological examination revealed obtundation, a leftsided torticollis and left head turn.

He had an ambulatory tetraparesis with marked ataxia, spontaneous knuckling and failure to correct abnormal paw placement of the left thoracic limb with a marked delay in correction of pelvic limb paw position. The remainder of the neurological examination was normal. The dog was prescribed paracetamol $10 \mathrm{mg} / \mathrm{kg}$ every 8 hours for 2 weeks, then dose was reduced to every 12 hours for an unspecific time. Four months later neurological status was unchanged. The lesion was localized to the C1-5 spinal cord segment based on the finding of tetraparesis with normal spinal reflexes together with proprioception deficits and no other neurological findings.
Prior to referral, magnetic resonance (MR) and computed tomography (CT; SENSE NeuroVascular 16 top-off coil, Phillips Healthcare, Best, the Netherlands) of the cervical spine were performed. Magnetic resonance imaging sequences included T2W_TSE_Sag, T2W_TSE_tra, T2W_mDixon_TSE Dor, T2W_TSE TS, B_FFE, T2W_FFE TS and revealed deviation of the cranial cervical spinal cord to the right with thinning of the epidural fat signal at the AA junction due to dorsolateral osseous compression (-Fig. 1). The dog was referred for potential surgical intervention to our centre and radiographs of the cervical spine in lateral and ventrodorsal projection were obtained and the CT scan was repeated because the diagnostic quality was insufficient for surgical planning. The CT (160-slice Aquillion PRIME Toshiba, Canon Medical Systems USA, Inc., United States) was performed in the transverse plane $(0.5 \mathrm{~mm}$ slice thickness $)$ and the sagittal and dorsal plane were reconstructed in $1 \mathrm{~mm}$ slice thickness, using the Aquilion PRIME Version 7 software by Toshiba. The radiographic study (Cuattro, Cloud DR, Heska AG, Switzerland) showed a step between the ventral arch of $\mathrm{C} 1$ and the vertebral body of $\mathrm{C} 2$. The area of the dens appeared to be in the centre between the dorsal and ventral lamina of $\mathrm{C} 1$, suggesting AA subluxation (-Fig. 1). Computed tomographic studies showed fusion of the basiocciput with the ventral arch of $\mathrm{C} 1$ on the left (occipitoatlantoaxial assimilation) and a hypoplastic occipital condyle on the right. The left atlas wing was distorted due to the fusion. A disconnected ossicle, suspected to be an os odontoideum, was overlying the occipitoatlantal junction. The axis had a shortened odontoid process, the cranial articular foveae were slightly rotated and the dorsal spinous process deviated to the left (-Fig. 1). Preoperative serum biochemistry was unremarkable. Conservative and surgical management options were discussed with the owner. Although a sustained medical management plan had not been adhered to prior to referral, it was

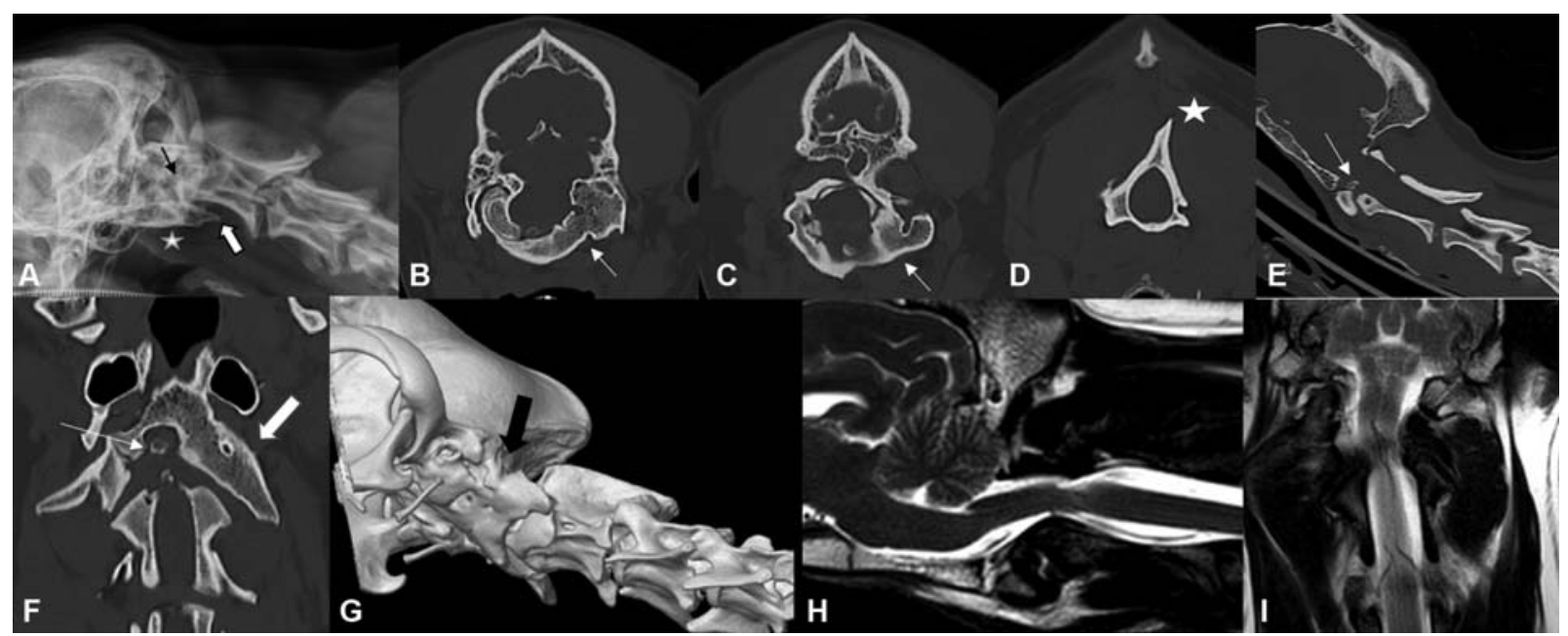

Fig. 1 Radiograph, computed tomography and magnetic resonance images showing conformational changes, (A) right-lateral radiographic view of the craniocervical junction, showing fusion of the skull and atlas ( ${ }^{*}$ ), suggesting of dens hypoplasia (thin arrow) and mild atlanto-axial subluxation/ overlapping (arrow), (B and C) transverse sequence at the level of the left-sided atlantooccipital assimilation (arrow), (D) transverse sequence at the level of the axis, note the spinous process rotated to the left $\left({ }^{*}\right),(\mathrm{E})$ Os odontoideum (arrow), (F) dorsal view of the occipitoatlantoaxial region; atlantooccipital assimilation (arrow) and os odontoideum (long arrow), (G) three-dimensional reconstruction displaying the fusion of the area of the left occipital condyle with the atlas (arrow), (H) T2-weighted sagittal view of the craniocervical area with narrowing at the atlantoaxial (AA) junction, (I) dorsal T2-weighted view showing the deviation of the spinal cord to the right and thinning of the epidural fat signal at the AA junction. 
considered less likely to result in long-term improvement in signs. The owners elected for surgical management.

\section{Surgical Technique}

The dog was positioned in dorsal recumbency with the head and neck extended and a ventral midline approach to the AA joint was made facilitating opening of the AA joint capsule, ${ }^{17,18}$ then debridement of the articular cartilage using a high-speed burr was performed. Following this, the AA joint was compressed using forceps and fixed in this position with two Steinmann pins placed. Autologous cancellous bone graft was harvested from both humeri and impacted in between the atlas and axis. A three-dimensional (3D) printed, customdesigned and carefully contoured $2.5 \mathrm{~mm}$ thick locking plate was placed ventrally on the AA surface. The plate was manufactured by Fitzbionics Limited, Godalming, UK. CT scans of the patient were processed using Materialize MIMICS imaging software to generate $3 \mathrm{D}$ models of the bones and then the AA implant was designed using Siemens Inc. NXCAD software to fit precisely across the ventral aspect of the AA joint (-Fig. 2). The implant was made using Direct Metal Laser Sintering 3D printing process in Titanium Grade 5 alloy and subsequently machined for threaded fixation holes. Seven $3.5 \mathrm{~mm}$ locking screws (Synthes, Wrington, UK) were implanted into previously established safe corridors on $3 \mathrm{D}$ reconstructed CT images. Three screws engaged the pedicles of C1-2 almost perpendicular to the ventral arch and one oblique, one screw was placed through articular fovea of $\mathrm{C} 1 / 2$ on the left and three placed in a dorsolateral oblique fashion through the pedicles of C2 (-Fig. 2). Intraoperative cefalexin (Zinacef, Glaxo Operations UK Ltd., Oxbridge, UK) at $22 \mathrm{mg} / \mathrm{kg}$ was administered intravenously. Postoperatively, orthogonal radiographs and CT images revealed appropriate implant positioning (-Fig. 3A,B). Screw placement accuracy comparing planned position to postoperative $\mathrm{CT}$ images revealed deviation of 0.5 to $3.3 \mathrm{~mm}$ (median: 1.8 ).

\section{Postoperative Care}

The dog was hospitalized for 5 days after surgery and received methadone (Comfortan, Eurovet by Animal Health
BV, Bladel, Netherlands) intravenously at $0.02 \mathrm{mg} / \mathrm{kg}$ every 4 to 6 hours alongside meloxicam (Metacam, Boehringer Ingelheim, Ingelheim/Rhein, Germany). Cefalexin (Therios, Ceva Animal Health Ltd., Amersham, UK) was continued 15 m/kg orally twice daily for 10 days. The patient had a persistent ambulatory tetraparesis with generalized proprioceptive ataxia, and delayed hopping reaction on the left thoracic limb together with a low head and neck carriage. Postoperative complications included seroma formation and a right Horner's syndrome. The dog was discharged with activity restriction to crate confinement and 5 to 10 minutes leash walks with a harness up to five times daily for 6 weeks.

\section{Follow-Up}

Clinical reassessment was performed at 2 and 6 weeks, and 3, 6 and 9 months. Orthogonal radiographs (-Fig. 3A,B) and repeated CT were performed immediately postoperatively, and 3 and 9 months after surgery (-Figs. 3C,D and 4). Two weeks after surgery, the dog received meloxicam once daily, which provided sufficient analgesia. He displayed a normal gait, was able to move his head and neck without restriction but continued to have a low-neck carriage. The seroma resolved but right Horner's syndrome persisted. No other neurological abnormalities were detected. At 6 weeks postoperatively, the dog no longer required analgesia and the right Horner's syndrome had resolved with some degree of miosis persisting. Neurological examination was otherwise within normal limits. Initial daily exercise of 5 minutes, 3-5 times, was increased by 5 minutes each week. Orthogonal radiographs at the 6 weeks postoperatively revealed satisfactory implant positioning. ACT scan performed 3 months after surgery showed unchanged implant positioning, no screw loosening or implant breakage and mild new bone formation between the left-sided caudal articular fovea of $\mathrm{C} 1$ and cranial articular surface of $\mathrm{C} 2$. Off leash exercise was gradually re-introduced. At 6 and 9 months after surgery, the Horner's syndrome had resolved completely and the gait was normal. Postural reactions were normal in all four limbs and he displayed a good range of motion of the neck without signs of pain on palpation or flexion. A subtle left-sided torticollis remained. Computed tomographic images obtained
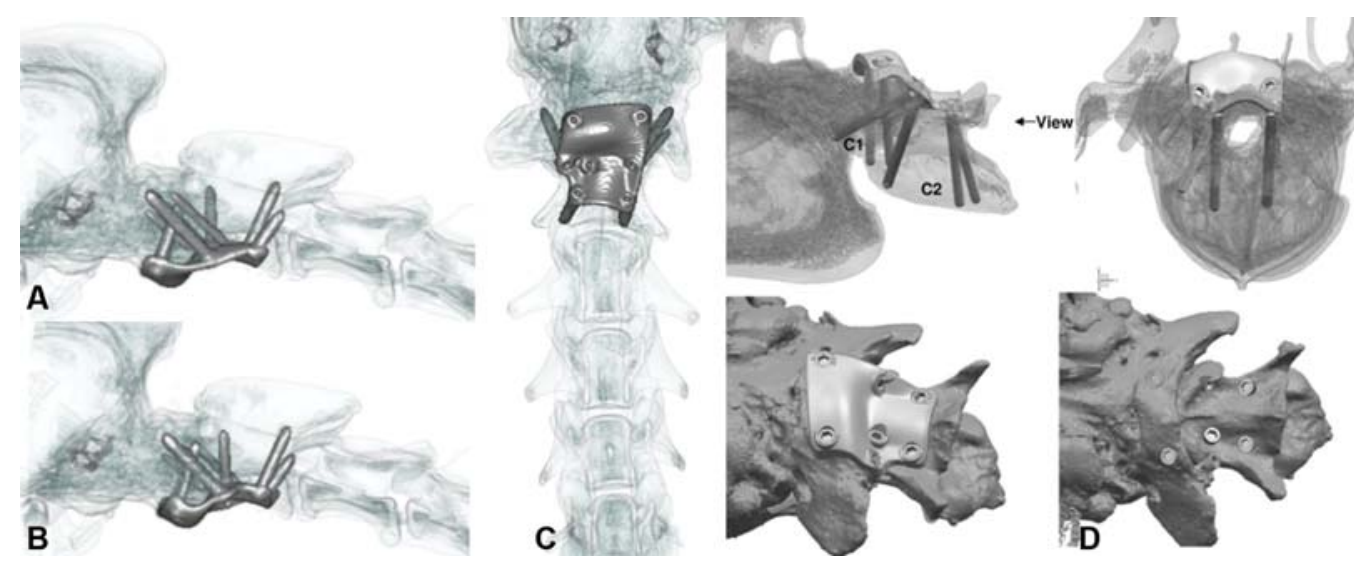

Fig. 2 (A) Left-sided sagittal three-dimensional (3D) computed tomographic reconstruction at the 9 months recheck, (B) right-sided sagittal plane, $(C)$ ventral view of 3D reconstruction and (D) preoperative implant drawing. 


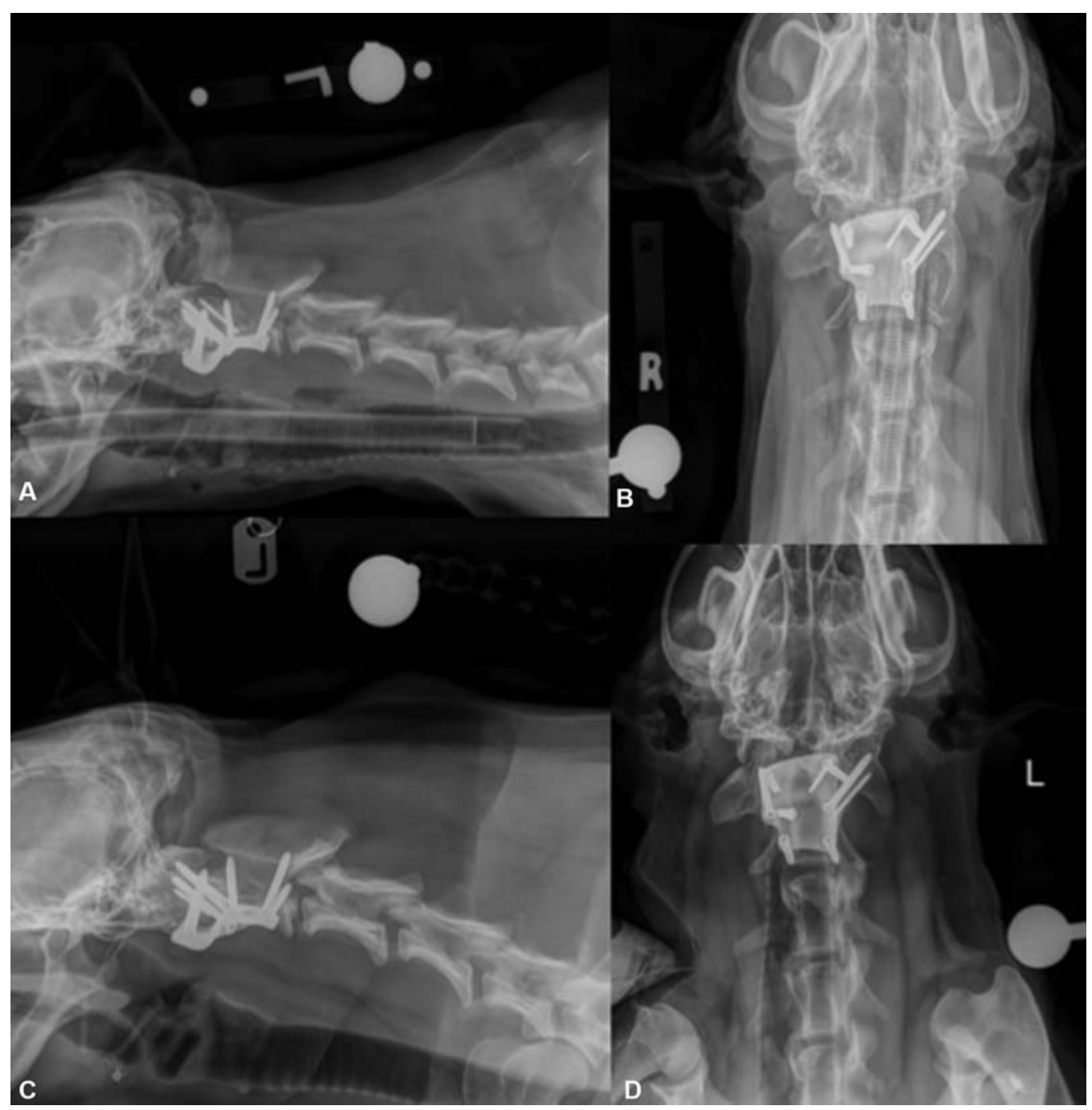

Fig. 3 Left-lateral and ventrodorsal radiographs of the implant. (A and B) immediate postoperative images (C and D) obtained at the 9 months recheck.

9 months after surgery revealed no subsidence, loosening or breakage of the implants ( - Figs. 2 and $\mathbf{4}$ ). New bone formation was present surrounding the plate and filling $>90 \%$ of the AAjoint space (-Fig. 4). The owner reported no signs of pain and no restriction in his exercise.

\section{Discussion}

This is the first report of a Border Collie with OAAM. Combination of radiographs, CT and MRIs enabled a detailed description of malformations and malarticulation. Without the ability to simultaneously compare CT with 3D reconstruction and MRI antemortem visualization is difficult. ${ }^{12,14}$ Our case was diagnosed with occipitoatlantal assimilation and suspected os odontoideum. The aetiology of os odontoideum is undetermined as could be the result of an embryological defect or due to postnatal fracture of the apex of the dens. ${ }^{15,16}$ All detected anomalies could be explained by failure of re-segmentation of the proatlas, responsible for the development of the dens apex, apical, cruciate and alar ligaments, occipital condyles, occipital bone, the superior portion of the posterior arch of $\mathrm{C} 1$ and lateral mass of $\mathrm{C} 2$, to name a few and the first spinal sclerotome forming the dens, the anterior arch of $\mathrm{C} 1$ and the inferior portion of the posterior arch of $C 1.2,5,6,11-14$ Treatment guidelines in human medicine are independent of the underlying aetiology. Fusion of the skull with the atlas leads to alteration in stress load and movement at this segment and exacerbates stress onto the AA joint. It is hypothesized this results in chronic instability of the AA joint with risk of vascular or spinal cord injury. ${ }^{1,2,6,8,12,15}$ Development of neurological signs is proposed to be influenced by the shape of the os odontoideum. 2,15 Surgical treatment is recommended in OAAM cases with neurological deficits, particularly if associated with a loose ossicle suspected to be part of the dens. ${ }^{12,14-16}$ There are four previous cases described in the veterinary literature, all of which had different surgical techniques, which are summarized in - Table 1. ${ }^{4,7,8}$ The most important cause of surgical failure is implant failure and failure to achieve osseous fusion. ${ }^{19}$ This is because the craniovertebral area is a very mobile joint. The risk is increased in a young and active patient and so we decided to design an anatomical plate with trajectory screw implantation to increase sturdiness of the construct. Precise and extensive preoperative planning, familiarization with the anatomy using $3 \mathrm{D}$ reconstruction and precise implant planning are thought to 


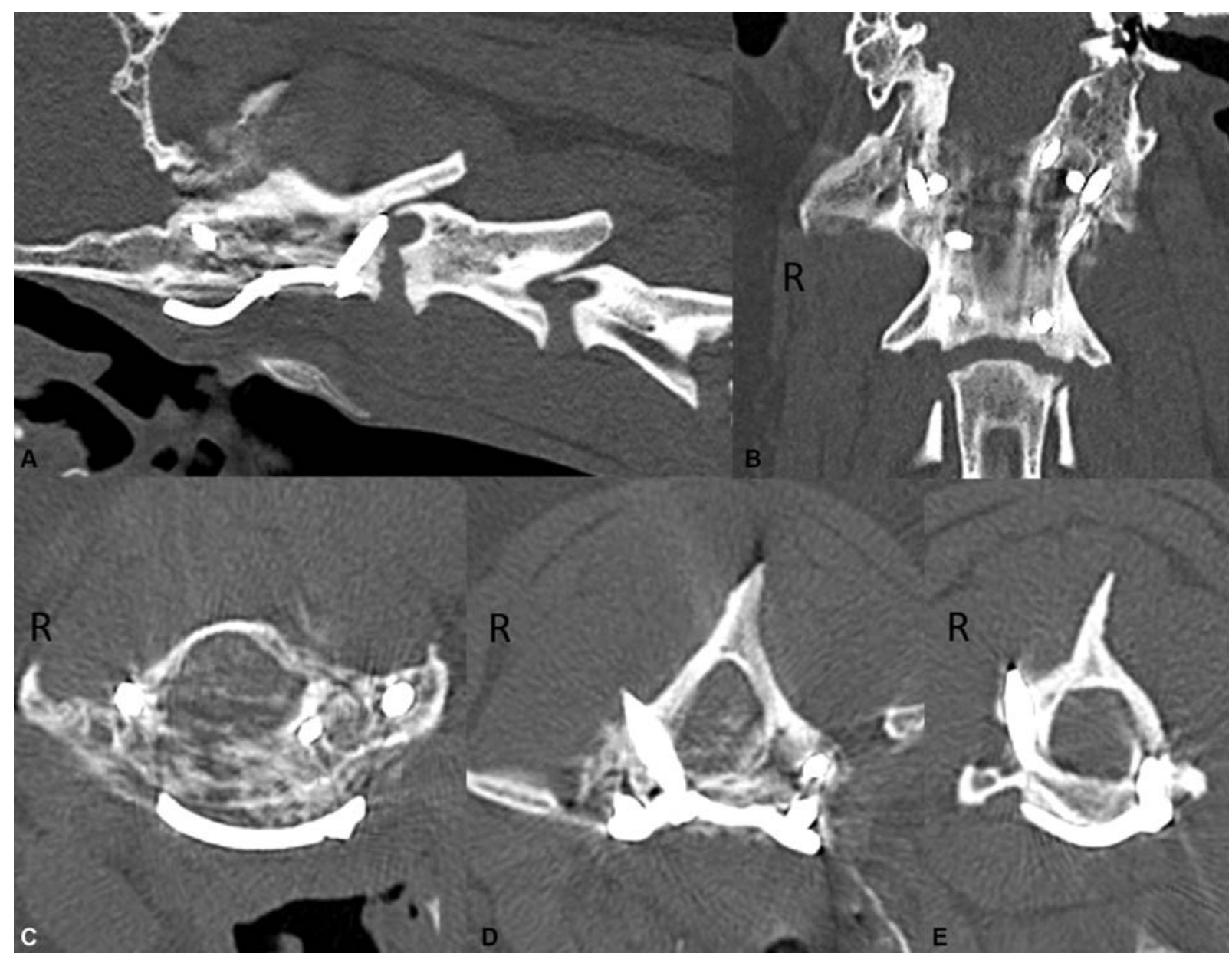

Fig. 4 Computed tomographic (CT) images 9 months after atlantoaxial (AA) arthrodesis: (A) Sagittal CT images of the fused atlantoaxial (AA) joint, (B) new bone formation within the right and left C1-2 joint, (C) transverse view of C1 with ventrally contoured plate, (D) transverse view of $C 2$ with wings of $C 1$ visible, visible new bone formation along the plate and $(E)$ transverse sequence of $C 2$.

have spared valuable intraoperative time with a surgical time of 225 minutes. Further, patient-specific implant design aided in establishing safe screw implantation corridors, reducing intraoperative risks of vertebral canal breach or vascular injury. Using a locking-plate implant, locking drill guides were used to ensure correct angulation of the locking screws. The use of an anatomical plate avoided intraoperative bending of the locking plate. Furthermore, bending of a locking implant could lead to damage the threaded screw holes. In addition, the use of locking screws is generally thought to be associated with decreased screw pull-out or implant migration. ${ }^{20}$

Postoperative complications included seroma formation, considered a minor complication which resolved without intervention and a right-sided Horner's syndrome. Horner's syndrome was also reported as a postoperative complication in a cat ${ }^{4}$ and $\operatorname{dogs}^{21,22}$ following a ventral cervical approach and is described in $0.06 \%$ of human patients ${ }^{23}$ undergoing anterior cervical discectomy and fusion due to injury to the sympathetic trunk. ${ }^{21-23}$ This may be limited by maintaining a midline surgical dissection and sub-periosteal dissection that aids in retractor placement beneath the longus colli muscle. ${ }^{23}$ Most of the human patients in the study by Traynelis and colleagues made at least a partial recovery without necessitating further intervention, as did the cases described in veterinary literature and our case. ${ }^{4,21-23}$ Occipitoatlantoaxial malformation, although rarely reported, should be considered as a differential diagnosis, even in adult animals. ${ }^{6,7,11}$ As in humans, signs might only occur later in life. The onset is often associated with minor trauma, although mild intermittent ataxia, paresis or cervical pain may have been present before, as noted in this case and previously reported in a cat and a dog. $2,4,7,12,14,16$ In conclusion, surgical treatment of AA instability due to OAAM with a customized locking plate provided a good outcome in this patient. This report illustrates the advances of new technologies, aiding in understanding and managing of complex vertebral malformations.

\section{Authors' Contributions}

All authors contributed to the concept of the study. C. Rotter was responsible for the acquisition of data. Data analysis and interpretation was performed by C. Rotter and N.F. All authors drafted, revised and approved of the submitted manuscript.

\section{Note}

Preliminary results were presented as a poster and abstract at the annual congress of the European Society of Veterinary 
Table 1 Overview of the literature of surgical treatment for animals with OAAM

\begin{tabular}{|c|c|c|c|c|c|c|}
\hline Signalment & Clinical signs & $\begin{array}{l}\text { Anatomical } \\
\text { description }\end{array}$ & $\begin{array}{l}\text { Surgical } \\
\text { technique }\end{array}$ & $\begin{array}{l}\text { Postoperative } \\
\text { cervical brace }\end{array}$ & Complications & Outcome \\
\hline $\mathrm{DSH}, 3 \mathrm{y}, \mathrm{MN}^{4}$ & $\begin{array}{l}\text { Tetraparesis } \\
\text { ataxia cervical } \\
\text { pain }\end{array}$ & $\begin{array}{l}\text { Malformed occi- } \\
\text { put + dens } \\
\text { AA-subluxation }\end{array}$ & $\begin{array}{l}\text { Odontectomy } \\
\text { Cross pinning } \\
\text { Bone graft }\end{array}$ & Yes & $\begin{array}{l}\text { Horner's } \\
\text { syndrome } \\
\text { right eye }\end{array}$ & 18 mo: Good \\
\hline $\begin{array}{l}\text { Shiba Inu, } 19 \mathrm{mo} \text {, } \\
25.5 \mathrm{~kg}, \mathrm{MN}^{7}\end{array}$ & Tetraparesis & $\begin{array}{l}\text { Fusion C1 to oc- } \\
\text { ciput } \\
\text { Oval osseous } \\
\text { structure in canal } \\
\text { Absent dorsal } \\
\text { arch C1 } \\
\text { AA-subluxation }\end{array}$ & $\begin{array}{l}\text { Two cortical } \\
\text { bone screws oc- } \\
\text { ciput-C1-C2 } \\
\text { Bone graft }\end{array}$ & No & - & $\begin{array}{l}26 \text { mo: postural } \\
\text { deficits, extend- } \\
\text { ed neck posture, } \\
\text { no pain }\end{array}$ \\
\hline $\begin{array}{l}\text { Weimaraner, } \\
5 \mathrm{mo}^{8}\end{array}$ & $\begin{array}{l}\text { Tetraparesis } \\
\text { ataxia cervical } \\
\text { pain }\end{array}$ & $\begin{array}{l}\text { Fusion C1-occi- } \\
\text { put } \\
\text { C1 dorsal arch } \\
\text { separated from } \\
\text { body } \\
\text { Dens aplasia } \\
\text { C1-2 instability }\end{array}$ & $\begin{array}{l}\text { ventral cross-pin- } \\
\text { ning figure-of- } \\
\text { eight wires (one } \\
\text { anchored with } \\
\text { screw in C2) } \\
\text { PMMA } \\
\text { Bone graft }\end{array}$ & Yes & $\begin{array}{l}\text { Implant loosen- } \\
\text { ing day } 3 \\
\text { Pin penetration } \\
\text { vertebral canal } \\
\text { Revision: two } \\
\text { 5-hole } 2.7 \mathrm{DC}- \\
\text { plates ventral } \\
\mathrm{C} 1-2>\text { Screw } \\
\text { penetration > } \\
\text { venous haemor- } \\
\text { rhage. Implant } \\
\text { loosening day } 11\end{array}$ & Euthanasia \\
\hline GSD, 5 y, $\mathrm{FN}^{8}$ & $\begin{array}{l}\text { Ataxia cervical } \\
\text { pain }\end{array}$ & $\begin{array}{l}\text { Fusion atlanto- } \\
\text { occipital joint } \\
\text { AA-subluxation }\end{array}$ & $\begin{array}{l}\text { Ventral: Odon- } \\
\text { tectomy }+\mathrm{K}- \\
\text { wires } \\
\text { Bone graft } \\
\text { Dorsal: wire occi- } \\
\text { put-axis }\end{array}$ & Yes & $\begin{array}{l}6 \text { wk: wire } \\
\text { breakage } \\
15 \text { wk: fusion } \\
40 \%\end{array}$ & Good \\
\hline
\end{tabular}

Abbreviations: AA, atlantoaxial; PMMA, poly methylmethacrylate; DSH, domestic short hair; OAAM, occipitoatlantoaxial malformation; GSD, German Sheperd dog.

Neurology/European College of Veterinary Neurology (ESVN-ECVN), Wroclaw, Poland, 13-14 September 2019.

\section{Funding}

Fitzpatrick Referrals Ltd. provided support in the form of salaries and materials for the authors. No third-party funding or support was received.

\section{Conflict of Interest}

The implant was designed by N.F. and manufactured by Fitzbionics Limited, which is directed by N.F. The other authors have no conflicts of interest to declare related to this report.

\section{Acknowledgments}

The authors acknowledge Jay Meswania, $\mathrm{PhD}$, for his assistance in implant design and manufacturing and are grateful to the University of Liverpool for their cooperation to use their magnetic resonance images.

\section{References}

1 Bailey CS, Morgan JP. Congenital spinal malformations. Vet Clin North Am Small Anim Pract 1992;22(04):985-1015

2 Electricwala AJ, Harsule A, Chavan V, Electricwala JT. Complete atlantooccipital assimilation with basilar invagination and atlantoaxial subluxation treated non-surgically: a case report. Cureus 2017;9(06):e1327. Doi: 10.7759/cureus.1327
3 Gunji M, Kawada S. A case of congenital occipitoatlantoaxial malformation in a wild Japanese Serow (Capricornis crispus). Bull Natl Mus Nat Sci Ser A 2019;45(01):31-33

4 Jaggy A, Hutto VL, Roberts RE, Oliver JE. Occipitoatlantoaxial malformation with atlantoaxial subluxation in a cat. J Small Anim Pract 1991;32(07):366-372

5 Seva JI, Gómez S, Pallarés FJ, Sánchez P, Bernabé A. Occipitoatlantoaxial malformation in an adult goat. J Vet Diagn Invest 2008; 20(05):654-656

6 Watson AG, de Lahunta A, Evans HE. Morphology and embryological interpretation of a congenital occipito-atlanto-axial malformation in a dog. Teratology 1988;38(05):451-459

7 Galban EM, Gilley RS, Long SN. Surgical stabilization of an occipitoatlantoaxial malformation in an adult dog. Vet Surg 2010;39(08):1001-1004

8 Read R, Brett S, Cahill J. Axial malformation in the dog. Aust Vet Pract 1987;17(04):184-189

9 Mayhew J. Congenital, genetic, and familial disorders. In: Large Animal Neurology. 2nd edition. Chichester, UK: Wiley-Blackwell; 2009:199-200

10 Sakamoto K, Kiupel M, Frank N, March PA. Vertebral malformation, syringomyelia, and ventricular septal defect in a dromedary camel (Camelius dromedarius). J Vet Diagn Invest 2004;16(04): 337-340

11 Petite A, McConnell F, De Stefani A, McKee M, Dennis R. Congenital occipito-atlanto-axial malformation in five dogs. In: Abstracts from the Annual Conference of the European Association of Veterinary Diagnostic Imaging; 2009;50(1): 111-129

12 Menezes AH. Craniocervical developmental anatomy and its implications. Childs Nerv Syst 2008;24(10):1109-1122 
13 Graham F, Rusbridge C, eds. Developmental anatomy. In: Syringomyelia-A Disorder of CSF Circulation. 1st edition. Berlin, Germany: Springer-Verlag; 2014:54-60

14 Menezes AH, Fenoy KA. Remnants of occipital vertebrae: proatlas segmentation abnormalities. Neurosurgery 2009;64(05):945-953, discussion 954

15 Klimo P Jr, Kan P, Rao G, Apfelbaum R, Brockmeyer D. Os odontoideum: presentation, diagnosis, and treatment in a series of 78 patients. J Neurosurg Spine 2008;9(04):332-342

16 Zhang Z, Wang H, Liu C. Acute traumatic cervical cord injury in pediatric patients with os odontoideum: a series of 6 patients. World Neurosurg 2015;83(06):1180.e1-1180.e6

17 Franch J, Lopez C. Atlas der chirurgischen Zugaenge - Hund und Katze. 2nd edition. Amsterdam, the Netherlands: Elsevier; 2010:126-130

18 Shores A, Brisson BA. Current Techniques in Canine and Feline Neurosurgery. 1st edition. Hoboken, NJ: Blackwell; 2017:450-451
19 Oda I, Abumi K, Sell LC, Haggerty CJ, Cunningham BW, McAfee PC. Biomechanical evaluation of five different occipito-atlanto-axial fixation techniques. Spine 1999;24(22):2377-2382

20 Bierdrzycki AH. Dynamic compression vs. locking plating - Is one "better"? A review of biomechanical principles and in vitro testing In: Barnhart MD, Maritato KC, eds. Locking Plates and Implants in Veterinary Orthopedics. Hoboken, NJ;2019:29-33

21 Rossmeisl JH Jr, White C, Pancotto TE, Bays A, Henao-Guerrero PN. Acute adverse events associated with ventral slot decompression in 546 dogs with cervical intervertebral disc disease. Vet Surg 2013;42(07):795-806

22 Boydell P. Horner's syndrome following cervical spinal surgery in the dog. J Small Anim Pract 1995;36(11):510-512

23 Traynelis VC, Malone HR, Smith ZA, et al. Rare complications of cervical spine surgery: Horner's Syndrome. Global Spine J 2017;7 (1, Suppl):103S-108S 